\title{
THE RDP - A CHALLENGE AND OPPORTUNITY
} (What Statistics and Operations Research can do for the RDP)

\section{Welcoming address by \\ ERICA FERREIRA \\ President of ORSSA}

$\mathrm{Mr}$ Chairman, Ladies and Gentlemen: It is an honour to welcome you on behalf of the Operations Research Society of South Africa to this seminar on the RDP jointly organised by the Operations Research Society of South Africa and the South African Statistical Association.

A special word of welcome and thanks to our speakers of the day from governmental departments and the Operations Research and Statistical communities, as well as our special guest from the UK, Dr Jonathan Rosenhead.

You are all very busy people and we appreciate the time and effort you have given our cause.

The new South Africa is 17 months old now. Since April 1994 much has changed and much has remained the same. But today's seminar is about changing the society in which we live, and I will concentrate on the positive changes. We have a government that is open and accessible to all the people of South Africa, and for the first time in our violent and conflict-ridden history we have a plan on the table that tries to involve all the peoples of our nation and to benefit society as a whole - the RDP. 
8

However, after 17 months the euphoria has mostly gone. People are asking why we are not seeing the results of the RDP. One answer may be that the RDP originated as the election promise of a political party seeking to gain power. As such it was an ambitious plan, but even so, still feasible. To my mind the biggest problem is that being part of an election campaign the benefits were promised on the short term, while reason clearly suggests this to be long term project.

A look at the RDP from an OR perspective shows it as a problem of global optimisation on a strategic level. It finds itself in the sphere of the so-called wicked problems. It is complex, it is shrouded in uncertainty, there is a lack of quantifiable data and there is a myriad of decision makers all with different objectives and world views. I have no doubt that an OR approach to these problems can help the decision makers to come to better grips with the problems before them.

My view that Operations Research can be applied is strengthened if I consider the key programmes of the RDP. They are:

(1) meeting basic needs,

(2) developing our human resource,

(3) building the economy,

(4) democratising the state and society, and

(5) implementing the RDP.

These five programmes cover things like providing housing and services, water and sanitation, energy and electrification, transport, a clean and healthy environment, nutrition and health care for all. It involves the allocation of scarce resources in matching supply and demand, finding cost-effective solutions to problems, and providing accountable decision-making. 
The OR literature is filled with reports on work done in all these areas. What better discipline than OR to make a contribution?

Then why hasn't it? Why is there at this stage little co-operation between the OR profession and governmental departments? Are government's ears closed to the voice of reason? Or has the voice of OR been too soft? (Which makes me think of a new meaning for the technical term "Soft OR"!)

I will consider today a success if it provides some of the answers to these questions, if it serves to make the OR community more enthusiastic about the RDP, if it shows us the way on how to become involved and if it opens the minds and doors of a few governmental offices.

One of the basic principles of the RDP is nation-building. I think this principle is the heart of the RDP. If the people of South Africa do no forgive and forget, if we do not rid ourselves of prejudice, if we do not have a global perspective, the RDP will not succeed. I invite you to open your minds and your hearts in a spirit of reconciliation - the true reconstruction and development must take place there.

I would like to end with an invitation to our honoured guests from the other side of the table - our speakers at this morning's session and delegates from governmental departments: If you have the time, please seriously consider attending this afternoon's session or at least the first talk of the afternoon, presented by a world renowned expert on the solution of so-called wicked problems, with vast experience on consulting to governments in the UK and other parts of the world. You may just hear a message that will change your life! 